THURSDAY, NOVEMBER 30, I88I

\section{ANTI-VIVISECTION versus HUMANITY}

THE physiology of the brain is a subject which has 1 long been matter of much speculation and of some experiment, but till twelve years ago little was known about it. The experiments of Flourens and others had taught us something about the functions of the cerebellum, and Broca's observations on disease had led him to localise speech in the third left frontal convolution; but with these exceptions the functions of the different parts of the cerebrum were almost entirely unknown; although, as a whole, it was regarded as the organ of thought. The experiments of Fritsch and Hitzig, published in I870, showed that the cortex of the brain could be excited by galvanic currents, although mechanical irritation seemed to have no effect upon it. When certain parts of the cortex were thus irritated in the dog, definite movements of the paws ensued.

In a series of experiments published in the West-Riding Asylum Reports for 1873, Dr. Ferrier confirmed these results, and greatly extended them by experimenting on guinea-pigs, rabbits, and cats, as well as by investigating more fully and precisely the various areas in the brain of the dog. Dr. Ferrier's most brilliant discoveries were due, however, to the happy thought of using monkeys as the subject of experiment. For though a general resemblance can be traced between the functions of different parts of the brain in rabbits or dogs, and in man, yet the brains of these animals are so little developed in comparison with that of man, that exact and definite conclusions regarding the human brain cannot be drawn from experiments on them. Monkeys resemble man more closely than quadrupeds in the more or less erect posture which they tend to assume, in the use of their hands and fingers as prehensile instruments, and even in their muscles of expression. Their brain, though less complicated than that of man, still corresponds closely with it in the general arrangement of the convolutions, and even in many details.

Dr. Ferrier's experiments were performed by anæsthetising the animal and removing a part of the skull so as to expose the brain. The animal was then allowed to recover either partially or completely from the anæsthetic. On the brain being stimulated by touching it with the wires of a battery at various points of its surface, definite movements resulted. A touch on one part, for example, would cause the animal to stretch out its paw as if to grasp some fruit, on another to raise its hand to its mouth, as if to convey the food into it, and another to move its mouth and tongue as if chewing. These motor areas were chiefly around the fissure of Rolando, towards the anterior part of the brain. Stimulation of the posterior parts appeared to cause sensation (not pain), a touch on one part causing the animal to look round as if it saw something unusual, on another to prick up its ears as if it heard something, and on others to move the nostrils and mouth as if it perceived some unusual smell or taste. Destruction of the surface of the brain at the parts whose stimulation caused movement resulted in the impairment or loss of the power of executing the corresponding movement voluntarily, and where stimulation VoL. Xxv.-No. $63^{\circ}$ caused sensation the destruction of the part diminished or destroyed the corresponding sensation of hearing, sight, or touch.

These experiments might seem at first sight necessarily to involve the infliction of great pain, and some unthinking people have loudly cried out against what they call horrid cruelty, and have denounced the experiments in no measured terms; yet the fact is that the animals experimented on suffer very little pain, and probably a single sportsman in a day's pheasant-shooting inflicts more pain than Dr. Ferrier has done in the whole course of his researches. Every one will understand this who has seen a child hurt its finger and cry bitterly for a few minutes, and then run cheerily about as soon as the wound was bound up.

The painful part of Dr. Ferrier's experiments, viz. the exposure of the brain, was performed under anæsthetics, and when the animals were allowed to recover they exhibited no signs of pain. Stimulation of the surface of the brain, even on the sensory areas, does not seem to cause pain. The effect of stimulating the motor areas and thus causing movements of the limbs in monkeys, appears to be simply to excite their wonder and curiosity at the extraordinary circumstance of their limbs moving independently of their volition.

The localisation of function in the brain is of exceeding interest as a simple addition to our knowledge of the wondrous mechanism of the body, but it is also of very great use in practical medicine. By means of it we are able to say, with considerable certainty, that the lesions which give rise to particular groups of symptoms are situated at this or that point in the brain. Ferrier found, for example, that stimulating one part of the brain would cause movements of the hand, ending in clenching of the fist, and if the stimulation were continued for a long time other muscles were involved, until at last the animal fell into an epileptic fit. Previous to Ferrier's researches we were in the dark regarding the origin of epileptic fits in man, but now when we find a fit beginning with clenching of the fist we can with considerable certainty localise the cause of it in a definite region of the brain. Not unfrequently epilepsy comes on after a blow or fall on the head, and may continue for months or years, completely ruining the patient's prospects, and perhaps ultimately destroying his intellect. In such cases the disease has been cured by the removal of the injured portion of skull; but before the researches of which we have been speaking showed how to localise the injury, this was impossible, except immediately after its infliction, and while the evidences of its position were unmistakable. Now, however, thanks to Dr. Ferrier, it is possible to operate successfully long after the injury, as the following case, which we extract from the British Medical Journal, will show :-

"A child, aged seven, received a blow from a poker ; it produced no external wound, and no scar or depression of bone remained. A year later the child had an epileptic fit, and continued to have fits daily for about seven years, with occasional periods of exacerbation, at which time the fits increased to twenty or thirty a day. At the end of this time Dr. Ferrier was asked to see the child in consultation ; tenderness was found over the right parietal region, with loss of power in the left hand and indistinct utterance from loss of muscular power in the lips. Trephining was decided upon, and Dr. Ferrier pointed out that the seat 
for trephining should be rather low down, to correspond to the centres for the arm and lips, which seemed affected. This was done; for eight weeks after the operation the child was free from fits, and at the periodical exacerbation the fits returned with always diminishing severity."

We have given only one instance, but Dr. Echeverria has collected $16_{5}$ cases of traumatic epilepsy, of which 64 per cent. were cured by trephining. Nor is it only in epilepsy that operative procedure, directed by the knowledge gained from Dr. Ferrier's researches, is useful. In abscess of the brain it guides the surgeon's knife to the spot where the pus has accumulated, and even when disease is due to tumours, it indicates their site, and enables them to be removed and the patient cured, as in a case reported in the Glasgow Medical Journal. It opens a new region in the treatment of diseases of the brain, of which it is impossible at present to see the limits ; and when we consider how recently the discoveries have been made it seems extraordinary that they should have already been productive of so much ben efit. Operations on the head are not however to be rashly undertaken, and in Dr. Ferrier's first experiments he found that injury to the brain was apt to spread beyond the primary limits of the lesion. Prof. Yeo therefore commenced a series of experiments for the purpose of discovering how far improved methods of operating would obviate the risk incurred in such operations, and his attempts have been very successful. These operations were carried out with a proper licence and certificate under the Vivisection Act. Dr. Ferrier embraced the opportunity of observing these animals, and aided Prof. Yeo by his advice, so that each experiment was utilised for the purpose of increasing our knowledge of localisation, and thus aiding diagnosis, as well as of improving the mode of treatment. For these observations he was summoned before the police-court last week by the Society for the Protection of Animals from Vivisection, on what grounds it is difficult to see. Though the summons was dismissed by the magistrate, the prosecution no doubt caused much worry to Dr. Ferrier, and might have caused expense, were it not that the British Medical Association took up and defended the case, in order to show its appreciation of the value of Dr. Ferrier's services both to medical science and suffering humanity. It is now about five years since the Vivisection Act was passed, and the late prosecution of Dr. Ferrier, while it shows how carefully the Act has been observed by physiologists, affords evidence that an Act which purported to be for the prevention of the abuse, is being converted into an instrument of annoyance to those who are best qualified for the use of experiments on animals. At the time the Act was passed many persons objected to it, on the ground that it was quite exceptional to legislate against an abuse which had never been proved to exist in this country. It has been shown by many statements made in the medical journals within the last few months that the Act is being administered in such a manner as seriously to interfere with the progress of science; and it seems not unlikely that the present insult to one of their number may rouse the medical profession to combined agitation against restraints on research for the acquisition of that knowledge which may enable them to lessen the sufferings or save the lives of their patients.

\section{EGYPT OF THE PAST}

The Egypt of the Past. By Erasmus Wilson, F.R.S. (London: Kegan Paul, Trench, and Co., r88r.)

THE increased interest taken in Ancient Egypt has produced of late two new histories in English, and two in French and German. The English histories are last in the field, and are those of Prof. Rawlinson and Sir Erasmus Wilson. These histories are not really the work of Egyptologists or experts like that of Brugsch Pacha and $M$. Maspero, but are attempts to produce readable works for popular purposes by writers interested in Egypt or writers of history, and have consequently all the merits and defects of that kind of way of treating the subject.

The present article is devoted to a consideration of the work of Prof. Wilson, which has last appeared, and is exclusively devoted to history. It comprises the history from the oldest days, the first appearance of the primitive Egyptian, the aboriginal of the Nile, till the last of the Pharaohs, the miserable Nectanebo, who abandoned his country, but not his wealth, to the foreigner B.C. 345 , and from that time till to-day a foreigner, in accordance with the law of monarchical nations, has ruled the country with the usual results.

The question of the first man of the Nile has not yet been settled, and he was probably one of those types which have disappeared from view altogether, and belongs to the fossilised remains of the planet. But history has little to seek about the prehistoric races and evidence of an antecedent state of dawning civilisation ; flint weapons are very scanty and obscure, and do not aid the solution of the problem. The obscure period of "the followers of Horus" has no historical or chronological importance, and belongs to the hazy epoch known as mythical and immeasurable. Actual history, but not positive chronology, begins with Menes, and the facts ascribed to Menes are, according to historical criticism, such as can be accepted as credible.

It has been agreed to designate as the Old Empire that part of Egyptian history which glides from the first to the sixth dynasty. This comprises the Pyramidbuilders, most, if not all, of whose geometric sepulchres are situated in the plains of Memphis and its vicinity on the western bank of the Nile. Although no pyramid can be identified with any king of the first dynasty, and the names of monarchs are known only from official lists and after-recollections, a monument of the second dynasty from a private tomb is in the Ashmolean Museum at Oxford, and shows that the civilisation at that remote period had attained the same excellence as at the fourth. It was under this dynasty that the worship of animals-an African idea-arose, and if the pyramid of Sakkarah, with its numerous chambers, was, as supposed, an early sepulchre of the Apis, that edifice must have been erected under the second dynasty, with all its geometric regularity and architectural knowledge, four centuries after Menes. Certainly writing, sculpture, painting, the arts and sciences had attained a great advancement and development. Still further advancement is visible under the third dynasty, and in the tombs which lie around the Pyramid at Meidoom sculpture had then reached a high excellence, and the portrait of the individual as well executed as the 